\title{
Training English Language Pre-service Teachers Using a Team Based Learning Approach
}

\author{
Arshad Abd Samad ${ }^{1}$, Hawanum Husein ${ }^{2}$, Juridah Md Rashid ${ }^{3} \&$ Sharifah Zainab Syd Abd Rahman ${ }^{3}$ \\ ${ }^{1}$ Centre for the Advancement of Language Competence, Universiti Putra Malaysia, Serdang, Malaysia \\ ${ }^{2}$ Kajang, Selangor, Malaysia \\ ${ }^{3}$ Faculty of Educational Studies, Universiti Putra Malaysia, Serdang, Malaysia \\ Correspondence: Arshad Abd Samad, Centre for the Advancement of Language Competence, Universiti Putra \\ Malaysia, 43400 Serdang, Malaysia. Tel: 603 89467278. E-mail: arshad@educ.upm.edu.my
}

Received: September 1, 2014 Accepted: October 9, 2014 Online Published: December 17, 2014

doi:10.5539/elt.v8n1p44 URL: http://dx.doi.org/10.5539/elt.v8n1p44

\begin{abstract}
Team Based Learning which focuses on enhancing positive group dynamics is a relatively popular instructional approach in several disciplines such as Health Sciences and Business but has yet to gain popularity in Education. This paper examines the use of Team Based Learning in teacher training as well as the receptiveness towards the approach as indicated by a group of Teaching English as a Second Language teacher trainee. The trainees were asked to write diaries regarding their experiences working in a team during a course for a semester which were then collected in three cycles throughout the semester. Entries were analysed in terms of whether there were positive, negative or neutral reference to working in teams. All members of a team were also required to participate in individual micro teaching sessions for which they were evaluated. Findings indicate that Team Based Learning has a potential role in teacher training as positive entries outnumbered negative entries. Additionally, teams with high average micro teaching scores also had more positive diary entries.
\end{abstract}

Keywords: diary studies, team based learning, teacher education, teacher training, TESL

\section{Introduction}

\subsection{Understanding Team Based Learning}

In recent years, various educational approaches such as problem based learning, task based learning and project based learning have captured the imagination of educators. Each of these approaches has its own pedagogical goals and objectives. Problem based learning, for example, was first developed by Barrows (1986) in order to find a more practical, hands-on approach to teach student doctors as opposed to listening to traditional lectures. Task based learning, on the other hand, emphasizes the completion of authentic tasks by learners and is popular in language teaching and learning through the use of language related tasks. Project based learning, similarly, emphasizes learning by doing as well as the completion of personally meaningful projects that serve a clear educational purpose (Larmer \& Mergendoller, 2010). These educational approaches have emerged from a need to meet changing learning demands, cultures as well as new approaches and techniques slowly surface due to this need.

Team based learning (TBL) is a learner-centred and instructor-led educational approach introduced in the 70s by Michaelsen and has been described as being based on the notion of scaffolding and that people learn from their own experiences as well as the experiences of others (Gracia, Latorre, \& Peiró, 2008; Koles, Stolfi, Borges, Nelson, \& Parmelee, 2010). Although similar in some ways to cooperative learning and the more general collaborative learning approaches, TBL is more focused and is especially applicable at universities and other institutes of higher education. Unlike the other approaches which are designed to help learners learn content material, team based learning fosters positive group dynamics by encouraging better intra-group communicaton skills to achieve a common goal.

The relevance of TBL to tertiary level education is quite apparent in preparing undergraduate students for the workplace as many professions can expect work to be more effective and efficient when done in teams. Lencioni (2002), for example, argued that rather than finance, technology, and strategy, "it is teamwork that remains the ultimate competitive advantage" (p. vii). In the Malaysian context, the development of "soft skills" is regarded 
as an important aspect of a comprehensive education. The Malaysian Education blueprint 2013-2025 clearly states that "Malaysian education aspires to ensure that every student achieves their full potential" (pp. 2-5) and to achieve this, emphasis is given to six elements, one of which is Leadership Skills which is further detailed out into the four elements of entrepreneurship, resilience, emotional intelligence and strong communication skills. TBL has the obvious potential in contributing to this goal through its obvious emphasis on student engagement and interaction.

The potential of TBL is further emphasized by how several disciplines, especially business and medicine, have taken quite quickly to the approach. In management studies, Fairfield and London (2003) note that "with the ubiquity of groups in today's organizational settings, team-based learning has become common practice in management education" (p. 655). Similarly, in the Health Sciences, Shankar and Roopa (2009) describe how their students in an embroyology class prefer a modified form of TBL to the traditional lecture and conclude that practical topics can best be learnt through TBL. These observations made in other disciplines are relevant to teacher education as there are also practical components in teacher education such as the teaching practicum, micro-teaching sessions as well as practical demonstrations. The earlier observation by Fairfield and London is also indicative of how teachers are expected to work in schools-i.e. together with their peers rather than individually and on their own. Although teaching may be performed individually in their own classrooms, education involves groups of teachers working together to achieve a common goal. This is further emphasized by DuFour (2004), who considers the creation of a collaborative culture as an important element in developing a professional learning community within a school. He notes that "the powerful collaboration that characterizes professional learning communities is a systematic process in which teachers work together to analyze and improve their classroom practice. Teachers work in teams, engaging in an ongoing cycle of questions that promote deep team learning. This process, in turn, leads to higher levels of student achievement" (p. 8).

TBL is a fairly structured approach consisting of several obvious characteristics and hence, can be more readily adopted and easier for instructors to implement compared to other similar educational approaches. In training language teachers, TBL has the advantage of encouraging not only collegiality among future teachers but also the development of language proficiency through interaction among team members in a task oriented situation. These benefits of implementing a TBL approach in teacher education calls for a more serious and concerted effort to consider the approach in teaching education. This paper describes the implementation of a TBL based approach, referred to in the study as Team Oriented Teaching and Learning or TOTaL, which is specifically aimed for language teacher education. It examines the efficacy of TOTaL as a TBL approach according to the diary entries of 32 university students over a period of a semester while completing a course taught through TOTaL in the university's Teaching English as a Second Language Bachelor of Education programme.

\subsection{Team Based Learning and Other Educational Approaches}

Some may consider Team Based Learning (TBL) as similar to several other educational approaches, especially collaborative learning and cooperative learning. This belief is partially true as Gomez, Wu, and Passerrini (2009), for example, note that TBL and cooperative learning share an "instructor-driven structure of the team process" (p. 383). Nevertheless, on closer scrutiny, each of these approaches has its own defining features that distinguish it from the other two. While all three approaches require students to work in groups or teams and emphasise student accountability in completing assigned tasks, TBL can be considered more structured in its implementation as it consists of specific elements aimed specifically at developing the group's potential to work together effectively towards a common goal. In addition, TBL differs from collaborative learning as well as problem-based learning - another popular educational approach — by allowing for more student self-organisation. Another defining characteristic of TBL is that it involves more permanent teams as teams work together for an entire semester. This characteristic distinguishes it from problem-based learning where teams come together only to solve more complex "problem-like" tasks, or the collaborative learning approach where students tend to form teams and assign each other specific roles to complete a given task.

As mentioned earlier, TBL consists of specific features and elements which have helped it evolve into a stable educational approach. Michaelsen and Sweet (2008), who are most associated with the approach, outlined four essential elements of TBL which are the formation and management of teams or groups; student accountability to groups; feedback to students; and assignment design. Similar elements were identified by Koles et al. (2010) and Gomez et al. (2009), who also highlighted the importance of preparation and student readiness in their structured TBL designs. In terms of the formation and management of groups, they stressed the importance of overseeing the formation of groups in order to ensure the existence of diversity in skills and abilities within the groups. In this respect, they believed that instructors should form the groups. If students are allowed to choose their own team members, they will naturally tend to select those who are more similar to them, and thus creates 
the possibility of forming sub-groups and cliques. Oakley, Felder, Brent, and Elhajj (2004) concurred, citing studies that lauded the benefits of instructor-formed teams, as well as their own experiences that members of self-formed groups may have a higher propensity to cheat and cover for one another (p. 11). Finally, in relation to assignment design, Michaelsen and Sweet (2008) highlighted the importance of designing activities that are able to contribute to the development of the team while the members perform the task required of them.

Oakley et al. (2004) mentioned higher grades, learning at a deeper level, retaining information longer, acquiring greater communication skills, and gaining a better understanding of the environment in which they will be working as professionals as among the major advantages (p. 9) and among some of the more obvious benefits of Team Based Learning. Nevertheless, they caution that instructors must create an effective team structure within the classroom in order to enjoy these benefits. Merely placing students into groups may result in students working independently, "pooling their work with no discussion, and ... spend a great deal of time in conflict over work-related or personal issues" (Oakley et al., 2004, p. 13). Clearly, then, the benefits of team based learning are not automatic and major concerns that may affect students' receptiveness towards TBL such as group management, accountability to the team, and the overall outcome of team activity including the final grade received must be addressed. Nevertheless, several research studies have also indicated that students are responsive towards TBL. In the field of medical sciences, Shankar and Roopa (2008) as well as Haidet, O'Malley, and Richards (2002) report positive student attitudes to the approach. Haidet et al. (2002) observe that the approach is able to foster a high degree of interaction, ownership and enthusiasm among students.

\section{Method}

This study was conducted in a Malaysian university located close to the capital of Malaysia and involved 32 second year Bachelor of Education students who were enrolled in a Teaching of English Grammar class. The class met for two hours of lecture and two hours of tutorial over a 14-week semester. In this study, the TBL approach was conducted with the aim of helping the students prepare for the individual micro teaching assignment to be performed during the final week of the semester. The approach, referred to in the study as Team Oriented Teaching and Learning (TOTaL), employed the four essential elements of TBL suggested by Gomez et al. (2009), Michaelson and Sweet (2008) and Koles et al. (2010) described earlier in this paper. The major goals of the study were to assess the students' receptiveness towards a TBL approach and to examine the potential of implementing a TBL model for teacher training, specifically for Teaching English as a Second Language teacher trainees.

Students in the study were organised into teams with members for each team selected by the instructor based on their current CGPA. The student's CGPA was used in order to form mixed ability teams that can be considered generally equivalent to the other teams based on the academic performance of their members. During the first tutorial session, students were also informed of the importance of being accountable to their teams. They were also briefed regarding how the course will be assessed and reminded of the team dysfunctions to avoid (Lencioni, 2002) in order to achieve effective teamwork. With respect to feedback to students, teams were required to arrange for consultation sessions with the instructor at various stages of the course. Finally, early assignments were organised in order to facilitate team activities and, in step ladder fashion, were intended to lead up to further and more challenging assignments later in the course. The first assignment, for example, was done individually and required each student to come up with a grammar teaching activity. They would then share this activity with their team members as a means to complete their second assignment which was to video record one of their team members teaching grammar for ten minutes. Teams were then required to discuss the recording with the instructor in separate team-instructor sessions. This video recorded assignment is related to the students' final project of micro teaching which, although performed individually, would provide bonus marks for each team based on the performance of every member in the team.

Data in this study were collected through a questionnaire survey and diary entries. The students were required to fill in a questionnaire which, besides providing useful data for the researchers, was also intended to further sensitise the students to the requirements and challenges of team learning. The statements in the questionnaire were adapted from instruments used in various studies (Bresó et al., 2008). The questionnaire consisted of 20 statements related to TBL which were presented in a 5-point Likert scale format with a response of 5 indicating strong agreement to the statement while a response of 1 indicating that the respondent strongly disagrees. The statements aimed to elicit students' views regarding the four aspects of TBL which are group dynamics, benefits of TBL, benefits towards micro teaching and assessment during TBL. In this paper, however, the results of the questionnaire are not discussed as they have been discussed elsewhere (Samad, Rashid, Rahman, \& Hussein, 2014). Instead, the focus will be on data collected through diary entries, which are described in the following paragraph. 
In addition to data collected through the questionnaire, all students were also asked to keep a diary with a minimum of twenty entries as part of their course requirements. Studies using diaries are becoming more and more popular. Iada, Shrout, Laurenceau, and Bolger (2012) pointed out that in psychological research alone, 250 journals per year have reported diary results. They also reported that such studies are useful in examining "systematic change in experiences across days" (p. 278). In this present study, the students were asked to write anything they wanted to regard their experiences while attending the course, including their thoughts and opinions regarding the content of the course as well as their assignments. They were not specifically instructed to write about working in teams. Diaries were collected at three times during the semester in order to ensure that students did not write their twenty entries in one sitting. An example of a diary entry made by a student is given in Appendix A. In this paper, the number of responses made regarding working in teams were noted and analysed in terms of whether they expressed positive or negative views towards team learning. Additionally, the performance of students in a team during their micro-teaching session held at the end of the semester was analysed in relation to the number of responses regarding TBL made by each team. A high score on the micro teaching session coupled with an overall awareness or receptiveness towards TBL, indicated by the number of total and positive responses towards TBL respectively, was considered to signify a positive indication for using TBL in teacher training.

\section{Results}

The results of the study are presented and discussed in three sections. The first discusses the diary entries related to working in teams, the second examines patterns in diary entries according to teams, while the third section revolves around an analysis of the performance of the teams on the micro teaching assignment and receptiveness to TBL.

\subsection{Diary Entries Related to Working in Teams}

Diaries were collected three times during the period of the study, and entries were analysed in terms of the frequency and percentage of entries that refer to TBL as well as the nature of the comments made regarding TBL. The total number of entries and the nature of comments made on TBL during the study period are summarised in Table 1.

Table 1. Number of diary entries according to the nature of comments regarding team based learning (TBL)

\begin{tabular}{llllll}
\hline \multirow{2}{*}{$\begin{array}{l}\text { Collection } \\
\text { Date }\end{array}$} & $\begin{array}{l}\text { Total No. of } \\
\text { Entries }\end{array}$ & \multicolumn{4}{l}{ Nature of Comments Related to TBL } \\
\cline { 3 - 6 } & & Neutral & Positive & Negative & Total \\
\hline 12 March & 99 & 16 & $8(8.1 \%)$ & $3(3 \%)$ & 27 \\
9 May & 196 & 35 & $19(9.7 \%)$ & $6(3.1 \%)$ & 60 \\
13 June & 297 & 16 & $13(4.4 \%)$ & $3(1.0 \%)$ & 32 \\
Total & 592 & $67(11.32 \%)$ & $40(6.76 \%)$ & $12(2.03 \%)$ & 119 \\
\hline
\end{tabular}

Of the 99 entries made after the first 4 weeks of the semester on 12 March 2013, 27 (27.27\%) were comments related to team based learning. Of these 27 references, 16 (59.26\%) were non-judgmental or neutral, 8 (29.63\%) were generally positive comments regarding TBL while the remaining $3(11.11 \%)$ can be considered negative towards the approach. Between 12 March and 9 May, the number of diary entries doubled to 196, reflecting a double increase in the number of entries for neutral (35), positive (19) and total comments (60), respectively. Upon final collection, the total number of entries increased to 297; however, the total number of neutral, positive and negative comments as well as the total number of entries regarding TBL showed a decrease from the previous collection. In order to better understand the attitude of the teacher trainees towards TBL, the number of positive and negative entries made throughout the study period was examined. The pattern of positive and negative responses throughout the duration of the study can be more clearly seen in Figure 1. 


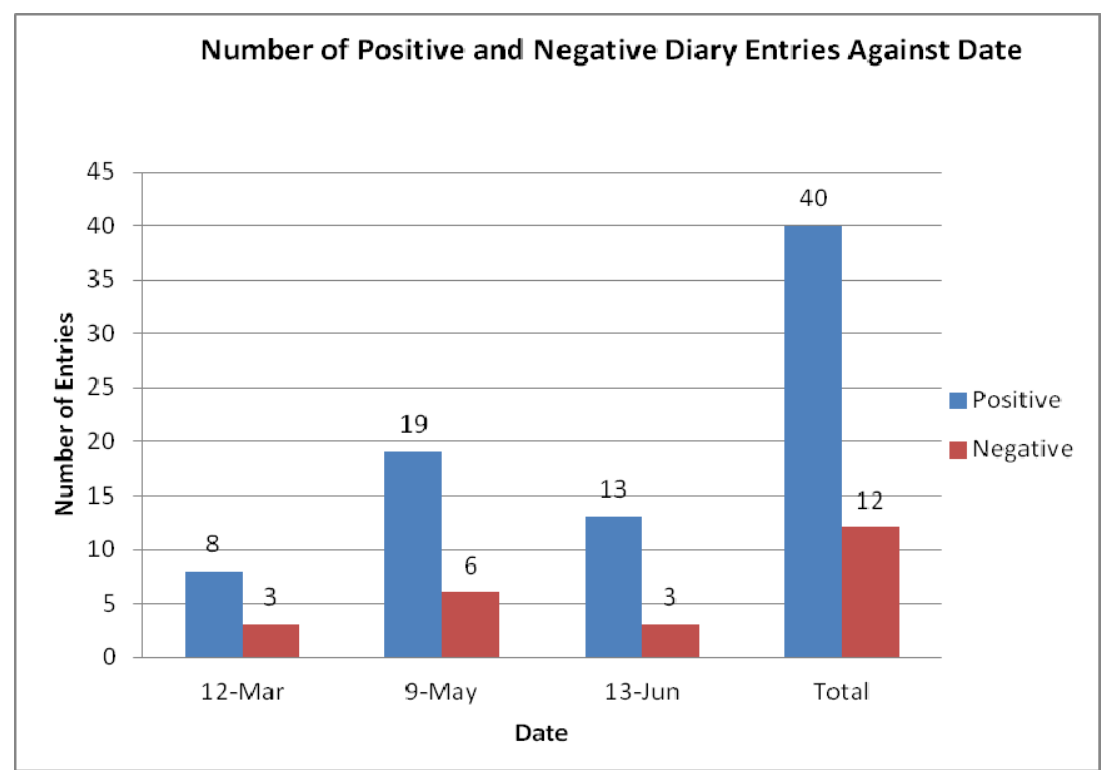

Figure 1. Number of positive and negative entries during the study

As can be clearly evidenced by Figure 1, there were more positive diary entries than negative ones. While the number of positive and negative diary entries can provide an insight into the students' receptiveness towards working in teams, an analysis of the actual entries can provide further information. Some of the examples of the positive entries regarding TBL, cited verbatim, included comments such as "We ask questions and clear all the confusions that we have with the help of each other ... Basically, we will help each other to understand more on what to do regarding the assignment", and "The group discussion was fun and exciting". There was consistent mention of working in team activities being "fun" as different students indicated this through entries at different points of the study. Some of these entries mentioned that "it was fun doing this activity, the topics which I could not really understand its contents, I really manage to understand well by this activity", and that the students "got a lot of feedback on individual assignment ... worked through confusion on lesson plans together. It was fun." Another benefit that seemed to emerge based on the entries was that there was greater socialisation among the students. One student felt that it was "an opportunity to mingle rather than stay inside the same group" while another "enjoyed completing the assignment" as he or she was able to "work with other people whom I have never work with before".

Negative entries, in contrast, included "I have never work with some of my group member because they are passive and very silence" and "I have never worked with any of them at all so, I'm feeling kind of excited and at the same time a little worry" which were both made at the outset of the study. This feeling of anxiety seemed to be warranted for some as at the end of the study, as some expressed their disappointment at the lack of commitment given by several team members: "We don't genuinely want to make the most of things, and we don't show enough support. Disappointed" and "Groupmate seems really busy and can't put time into work. Frustrated."

Both the positive and negative comments indicate the importance of ensuring that students are aware of the importance of communicating with their team members in order for all members to benefit from TBL. Initial anxiety of working with individuals they have never worked with before can be overcome with sufficient time and energy made by team members as well as the instructor in socialising members into the team.

\subsection{General Response Pattern towards Working in Teams}

Each student was required to perform a micro teaching session at the end of the semester. As a member of a team, each student was also expected to work together with other team members in preparation for this micro teaching session. The diary entries are an indication of how well the teams worked together. The positive and negative entries made by each of the five teams during each of the three cycles in the study are presented in Table 2 . Entries that are considered neutral, which mention working in teams but do not indicate either a positive or negative view towards it, are also included as they show awareness and receptiveness towards the idea of working in teams. 
Table 2. Number of neutral, positive and negative entries according to teams and cycles

\begin{tabular}{llllllllllllll}
\hline Team & \multicolumn{3}{l}{ 12 March } & \multicolumn{3}{c}{9 May } & \multicolumn{3}{c}{ 13 June } \\
\hline & TN & T+ & T- & TN & T+ & T- & TN & T+ & T- & TN & T+ & T- \\
A & 9 & 3 & 1 & 13 & 3 & 4 & 1 & 3 & 0 & 23 & 9 & 5 \\
B & 3 & 1 & 1 & 5 & 1 & 1 & 8 & 1 & 0 & 16 & 3 & 2 \\
C & 1 & 2 & 0 & 5 & 2 & 0 & 0 & 4 & 1 & 6 & 8 & 1 \\
D & 1 & 2 & 0 & 8 & 12 & 1 & 1 & 3 & 0 & 10 & 17 & 1 \\
E & 2 & 0 & 1 & 4 & 1 & 0 & 6 & 2 & 2 & 12 & 3 & 3
\end{tabular}

Note: $\mathrm{TN}=$ Total neutral entries; $\mathrm{T}+=$ Total positive entries; $\mathrm{T}-=$ Total negative entries.

Each team's response towards TBL throughout the semester was analysed according to the diary entries of their members at the three points when the diaries were collected. Some interesting observations were made when the responses at the three cycles were analysed. Team A, for example, had fewer neutral responses in their diary at the end of the third cycle compared to at the beginning of the programme. This may indicate that the members in the team, were beginning to form clearer opinions regarding working in teams. Team B, on the other hand, seems to be tentative towards the idea of working in groups as the neutral entries continued to rise throughout the semester. There were also few positive and negative entries as the team ended with only a total of 5 positive and negative entries at the end of the semester. This pattern is also observed in the entries made by Team E, although in the case of this team, there were more positive and negative comments made at the end of the semester compared to the beginning of the semester. The other two teams, Teams D and C, seem to express a positive view towards working in teams as the number of positive entries increased towards the end of the semester. Team D, in particular, ended up with the highest number of positive diary entries among the five teams.

In general, the data indicate a somewhat positive response to TBL. Three of the teams demonstrated a constant increase in positive responses from the first to the third cycles which may indicate that the views of members in these teams had become more positive towards the end of the semester. The members of these teams can be considered to have a positive view towards working in teams while the members of Teams B and E seem not to have formed any clear position regarding the matter.

\subsection{Team Performance and Diary Entries}

The number and type of entries of each team was compared to the teams' performance on the micro-teaching task. The average micro-teaching scores received by members of the five teams, A, B, C, D, and E were 77.9, $76.4,76.3,76.2$, and 75.8 , respectively.

In attempting to make some form of connection between the diary entries and performance on the micro teaching task, diary entries were analysed in two ways. First, the researchers determined whether the members of the teams were sensitive to the idea of working in teams by analysing the total number of diary entries related to TBL, regardless of whether these entries were neutral, positive or negative. The total number of diary entries was therefore considered as an indication of how aware and conscious the team members were to their experience of working in teams. Secondly, researchers ascertained whether the teams considered TBL a practical approach. This was analysed through the number of positive diary entries made in comparison to negative diary entries. A practicality or functionality score was computed by deducting the total number of negative entries from the total number of positive entries. The value of this simple equation is considered to indicate how practical or functional the teams considered Team Based Learning with higher scores indicating higher functionality. Figure 2 summarises both these analyses involving awareness and functionality for the five teams as well as each team's performance on the micro teaching task. 


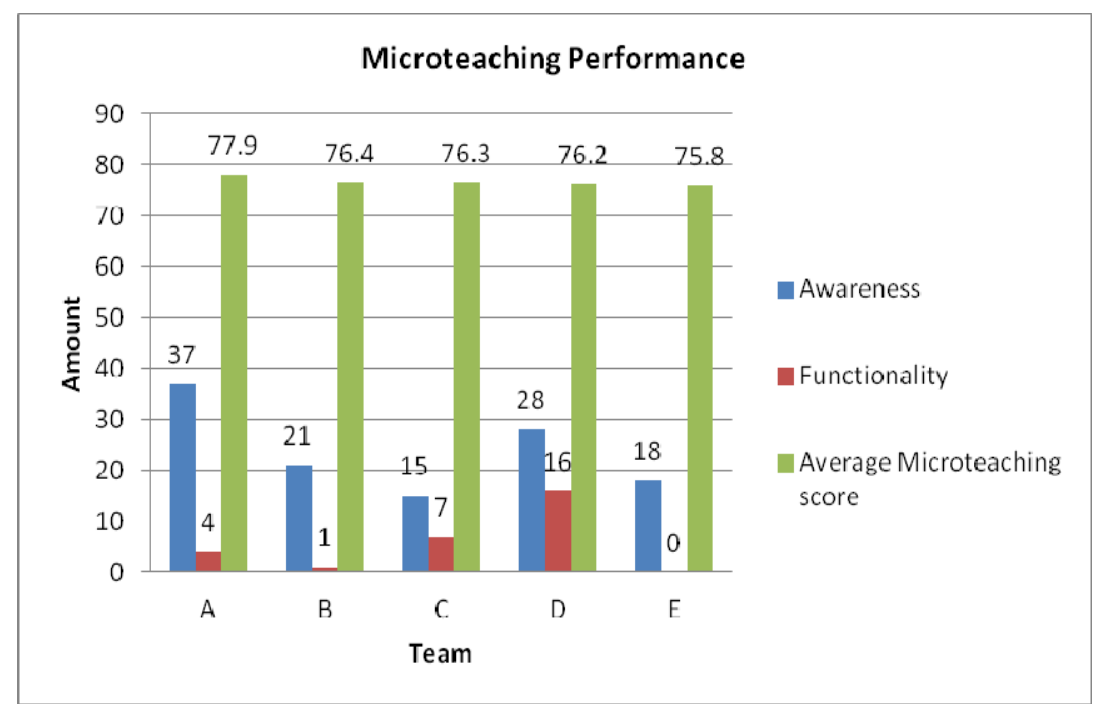

Figure 2. Micro teaching performance and views of teams towards TBL

Based on Figure 2, two observations are made. First, Team A which had the highest average score among the five teams also had the most number of entries related to working in teams. This may indicate that they were the most active in trying to perform as a team as their members ended up being more aware of team work tasks. Secondly, Team $\mathrm{E}$ which had the lowest average score was also the most ambivalent of the teams in terms of making positive and negative entries towards working in teams. This team ended up with an equal number of positive and negative diary entries at the end of the semester. Both these observations point to a generally positive outlook of using TBL in teacher education courses.

\section{Conclusion}

This study is an initial foray by the researchers into the implementation of team based learning (TBL) in teacher education courses at a Malaysian university. It began with the belief that TBL, by its very nature, can lead to greater awareness towards establishing collegiality and working in teams and consequently develop the relevant soft skills among students to make team work effective. A second relevant impetus to this study is the natural relevance of a team based approach to educating language teachers because of the emphasis placed on interaction by the approach. TBL in this study was implemented through an approach specifically designed for teacher trainees and is referred to in the study as the Team Oriented Teaching and Learning or TOTaL approach. This approach involved working in teams in order to complete a major end of semester micro teaching task. The analysis of diary entries in terms of frequency counts as well as content analysis of the type of entries made indicate that students have become more sensitive towards the requirements needed to work effectively in teams after being involved in the Team Oriented Teaching and Learning TBL approach used in this study. Diary entries also indicate that students form a generally positive view on the benefits and effectiveness of working in teams. These findings suggest a potential and positive role for Team Based Learning in Malaysian universities, particularly - but not limited to teacher education. However, the data also indicate that instructors will have to develop a greater sense of accountability among students in order for TBL to succeed. While this may seem an additional burden for the instructors, it is a goal which they can justifiably work towards in developing students with the appropriate personal qualities and abilities for teaching in institutions in the modern world. The results of this study also indicate that serious consideration in implementing Team Based Learning in teacher education in Malaysian universities is warranted.

\section{Acknowledgments}

This study was conducted through a grant received from the Centre for Academic Development (CADe), Universiti Putra Malaysia.

\section{References}

Barrows, H. S. (1986). A taxonomy of problem-based learning methods. Medical Education, 20, 481-486.

Bresó, I., Javier Gracia, F., Latorre, F., \& Peiró, J. M. (2008). Development and Validation of the Team Learning Questionnaire. Comportamento Organizacional E Gestão, 14(2), 145-160. 
DuFour, R. (2004). What is a "professional learning community"? Educational Leadership, 61(8), 6-11.

Fairfield, K. D., \& London, M. B. (2003). Turning into the music of groups: A metaphor for Team-based Learning in management education. Journal of Management Education, 27, 654-672.

Gomez, E. A., Wu, D., \& Passerini, K. (2010). Computer-supported team-based learning: The impact of motivation, enjoyment and team contributions on learning outcomes. Computers \& Education, 55, 378-390.

Haidet, P., O’Malley, K. J., \& Richards, B. (2002). An Initial Experience with “Team Learning” in Medical Education. Academic Medicine, 77(1), 40-44.

Iada, M., Shrout, P. E., Laurenceau, J., \& Bolger, N. (2012). Using diary methods in psychological research. In H. Cooper (Ed.), APA Handbook of Research Methods in Psychology (Vol. 1, Foundations, Planning, Measures and Psychometrics, pp. 277-305). Washington, DC: American Psychological Association.

Koles, P. G., Stolfi, A., Borges, N. J., Nelson, S., \& Parmelee, D. X. (2010). The Impact of Team-Based Learning on Medical Students' Academic Performance. Academic Medicine, 85(11), 1739-1745.

Larmer, J., \& Mergendoller, J. R. (2010). Seven essentials for project based learning. Educational Leadership, 68(1), 34-37.

Lencioni, P. (2002). The five dysfunctions of teams: A leadership fable. Jossey-Bass. San Francisco, CA.

Michaelsen, L. K., \& Sweet, M. (2008). The essential elements of Team-Based Learning. New Directions for Teaching and Learning, 116, 7-27.

Ministry of Education, Malaysia. (2013). Malaysian Education Blueprint 2013-2025 (Preschool to Post-Secondary Education). Malaysia: Malaysian Ministry of Education.

Oakley, B., Felder, R. M., Brent, R., \& Elhajj, I. (2004). Turning student groups into effective teams. Journal of Student Centered Learning, 2(1), 9-34.

Samad, A. A., Rashid, J. M., Rahman, S. Z. S. A., \& Hussein, H. (2014). Investigating the implementation of team based learning in a university level teacher education course. International Journal of Asian Social Science, 4(2), 249-257.

Shankar, N., \& Roopa, R. (2009). Evaluation of a modified team based learning method for teaching general embryology to 1st year medical graduate students. Indian Journal of Medical Science, 63, 4-12.

\section{Appendix A}

Example of Diary Entry

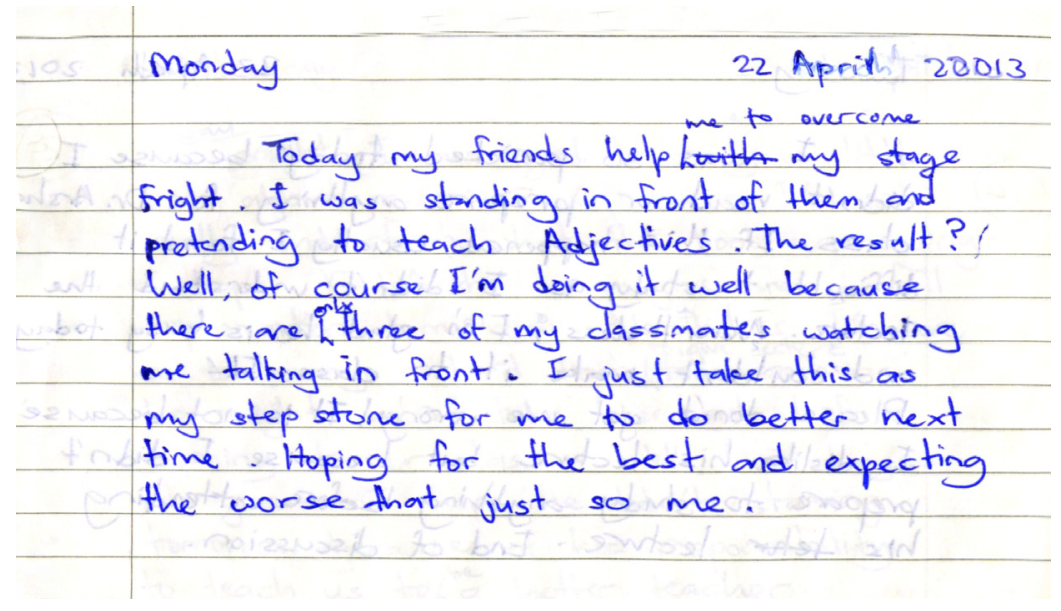

\section{Copyrights}

Copyright for this article is retained by the author(s), with first publication rights granted to the journal.

This is an open-access article distributed under the terms and conditions of the Creative Commons Attribution license (http://creativecommons.org/licenses/by/3.0/). 